tattoos are a stigma of borderline personality disorder, or indeed abuse, removal should be more readily available.

VIRKUNEN, M. (1976) Self-mutilation in antisocial personality (disorder). Acta Psychiatrica Scandinavica, 54, 347-352.

HEATHER INCH RHODRI HUWS

Rotherham District General Hospital

Moorgate Road

Oakwood

Rotherham S60 2UD

\section{Postage stamp test for sexual disorders}

SIR: Sexual anxiety is commonly seen in India, presumably because of the value attached to semen in folklore. Symptoms may also be exacerbated by the lack of sexual education. For example, loss of semen is equated with loss of blood in Ayurveda, the indigenous system of medicine. Impotence also carries a grave connotation. Dhat, a syndrome characterised by undue concern about the debilitating effect of the passage of semen (ICD-10), is a frequent diagnosis in psychiatric and urological clinics in the Indian subcontinent. Koro, a related syndrome involving anxiety that the penis will retract into the abdomen and cause death, is seen in neighbouring countries.

Most hospitals in developing countries do not possess instrumentation to assess nocturnal penile tumescence. This is required in order to rule out organic causes for the loss of erection. It is also useful for reassuring patients. In this context, we became aware of the 'postage stamp test' through 'word of mouth'. We now routinely use this test in our clinic to document nocturnal penile tumescence.

Following preliminary assessments, we explain to patients with erectile or ejaculatory problems that nocturnal erections provide strong evidence for potency. Each patient is asked to paste two postage stamps on his penis before going to bed. Patients are asked to repeat this procedure for four consecutive nights. Breakage or removal of the stamps on awakening is taken as suggestive evidence for nocturnal erection.

The postage stamp test has proved invaluable for reassuring our patients. We also use it as a guide in our investigations. In a recent survey, 69 patients presenting with 'dhat' were asked to take the test. All but six scored positively. Further investigations to identify possible organic aetiological factors were carried out on the patients who scored negatively on the test. All patients received relaxation or behaviour therapy (Jacobson, 1938; Annon, 1976). Patients who scored positively on the postage stamp test experienced modest to total improvement, while the patients with negative scores had uniformly discouraging results. This test is simple, inexpensive, and merits more extensive application. We would appreciate correspondence from other professionals who have used it.

Annon, J. S. (1976) Behavioral Therapy of Sexual Disorders. Hagerstown: Harper and Row.

JACOBSON, E. (1938) Progressive Relaxation. Chicago: University of Chicago Press.

$\begin{array}{lr} & \text { S. K. DAS } \\ & \text { S. N. DESHPANDE } \\ \text { R. S. NAGPAL }\end{array}$

Correspondence: $\operatorname{Dr}$ V. L. Nimgaonkar, Room 993, WPIC, 3811 O'Hara Street, Pittsburgh, PA 15213, USA

\section{Gastric emptying and bloating in anorexia nervosa}

SIR: The double-blind study of Stacher et al (Journal, March 1993, 162, 398-402) showed that cisapride, a gastro-prokinetic drug, accelerated gastric emptying, diminished gastric bloating/pain and led to shortterm weight gain in 12 Austrian patients with primary anorexia nervosa. This finding may be particularly germane to anorexia nervosa examined from a historical and cross-cultural perspective.

An increasing number of historical studies have shown that early-onset anorexic women rarely used the fear of fatness as a reason for food refusal. Instead, they commonly exhibited gastric grievances and were given such labels as 'apepsia hysterica', 'bradypepsia', 'anorexia atonica', 'nervous dyspepsia', 'dyspeptic neurasthenia', 'hyperaesthesias of the stomach', or simply 'visceral neurosis' (Parry-Jones, 1991; Shorter, 1987). It was not until about 1960 that the now characteristic fear of fatness appeared regularly as a predominant motive for self-imposed starvation in scientific writings on anorexia nervosa (Casper, 1983). This probably reflected a cultural awareness of weight-control problems in the 1940s following the Depression years, generated by increasing affluence and availability of food, which together propelled the fear of fatness into the foreground as an explanation for women's intentional maintenance of a low body weight. At the same time, interest in gastric symptoms among anorexic patients has waned, even though delayed gastric emptying produces exaggerated stomach fullness, satiety, 